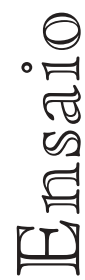
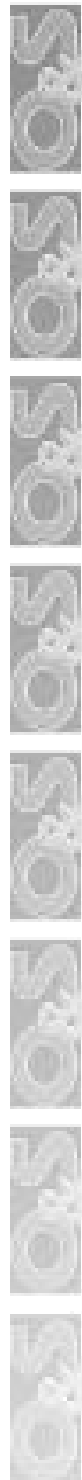

F 


\title{
CLICFILIOS.COM.RR:O DILENA $\mathbb{D E} \mathbb{S} \mathbb{E} G \mathbb{U} \mathbb{R} \mathbb{E} \mathbb{M} \mathbb{F} \mathbb{R} \mathbb{E} \mathbb{N} \mathbb{E}$ OU

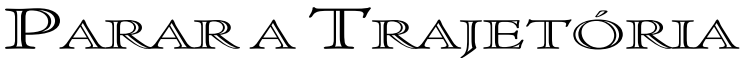

Fábio Frezatti*

$\mathbb{R} \mathbb{E S U M O}$

I

rês pessoas com distintas formações profissionais, trabalhando juntas, criaram um site de prestação de serviços para pais de crianças e adolescentes por meio de conteúdos disponíveis na Internet. O projeto contou tanto com o apoio financeiro de um patrocinador como o apoio profissional de vários especialistas que proporcionaram qualidade ao veículo. Dessa maneira, o site ganhou reconhecimento como significativo instrumento de apoio informativo às famílias em questões triviais e mesmo complexas da criação de filhos o que, nesse formato, até então era inédito no Brasil. Com o final do patrocínio, a perspectiva de desenvolvimento futuro e demanda por novos investimentos, as empreendedoras enfrentaram um dilema existencial: manter o site da forma como estava, crescer, diversificar, associar-se a outras organizações ou extinguir o projeto. 0 que fazer? Várias seriam as alternativas possíveis na estratégia de vida do projeto e correspondentes distintos graus de satisfação pessoal, envolvimento financeiro e risco a identificar e equacionar.

\begin{abstract}

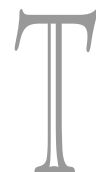

hree persons with different academic background, working together, built a website specifically aimed at supporting parents of children and teenagers through Internet contents. The project had financial and professional aid that made it possible to offer a quality service. Thus, the website was recognized as a significant effort to provide information, supporting families in ordinary or complex issues related to how to raise children, which was something new in Brazil. At the end of the sponsorship payments, the future development perspective required new investments and the entrepreneurs faced a difficult dilemma: to keep the site the way it was, grow, diversify, join with another entity or extinguish the project. What should they do? Several alternatives were available, involving different levels of personal satisfaction, financial commitment and risk.
\end{abstract}

*Prof. e Coordenador do Programa de Pós-Graduação em Contabilidade e Controladoria da FEA/USP 


\section{INTRODUÇ $\mathbb{A} O: U \mathbb{R}$ DESAFIO, UNA RESPOSTA}

omo resultado da ausência de informações úteis e confiáveis, três mães de adolescentes começaram a trabalhar juntas na construção de um website, com o objetivo de proporcionar aos pais de crianças e adolescentes orientações para que pudessem cuidar de seus filhos nas várias etapas de suas vidas. O raciocino que permeava o início do projeto era que alguma empresa pudesse patrocinar um projeto de Internet, com a criação de um site de consulta, aberto ao público em geral, sem custos para os usuários. O benefício a ser gerado para o patrocinador consistiria em usar tal veículo para divulgação de seus produtos. Uma importante empresa multinacional se propôs a apoiar o projeto e se tornou o primeiro patrocinador dosite, que foi denominado www.clicfilhos.com.br. Foi desenhado para cobrir áreas amplas, tais como dar apoio aos pais nas suas conversas com adolescentes sobre AIDS e mesmo trazer orientações sobre como agir em caso de doenças ocorridas com um bebê de poucos meses.

O planejamento dos novos conteúdos temáticos foi desenvolvido de maneira sistemática a partir da sensibilidade da prioridade do que tratar, levando em conta a demanda dos clientes. Periodicamente, através de algumas reuniões, as discussões de conteúdo foram feitas. Como seqüência, os escritores produziram drafts do que seria necessário e um especialista foi identificado para produzir o material, o qual foi editado e tornado disponível através do site. Caso uma entidade queira produzir os conteúdos, independentemente de para quais objetivos, esse seria o grande diferencial. Outra alternativa seria empregar o grupo e pagálo de acordo com sua produção, o que deveria estar sintonizado com a demanda, a partir de um orçamento estabelecido.

O projeto caminhou bem durante algum tempo, até que o período de patrocínio se extinguiu e os recursos de sustentação do dia-a-dia do projeto pararam de entrar. Não havia nenhuma chance de manutenção dos serviços sem dinheiro novo, tanto para as questões tecnológicas agora necessárias com relativa urgência, como de pessoal para a operacionalização das atividades já existentes. Planos para o futuro elas tinham e isso era claro; contudo, as várias tentativas para buscar recursos para financiar as futuras atividades do projeto, tanto na iniciativa privada, como governamental ou mesmo entre as ONGs haviam fracassado. A combinação de ambiente recessivo e ausência de um interlocutor adequado gerou a percepção de que a questão básica de direcionamento do site voltava ao grupo na rediscussão da continuidade do projeto. O dilema enfrentado consistia em decidir: o que fazer com o site?

\section{$\mathbb{A N T}_{\mathbb{N}} C \mathbb{E} D \mathbb{E} \mathbb{N} \mathbb{E}$ DO DESEMIPENHO DO SITE}

O site foi desenhado de acordo com o desejo e sonho das empreendedoras e teve na perspectiva e experiência de três mães a identificação do que seria útil aos pais em geral em termos de necessidade de orientação para criação de seus filhos. Cida, a diretora financeira do projeto tem formação em Serviço Social. Ela se dedicou a obter os fundos necessários e negociou prazos com os outros agentes. Celiza, responsável pelas operações, a engenheira do grupo, lidou com o desenvolvimento do material para ser usado e manteve o site funcionando. Milena, a executiva de marketing, correu atrás dos possíveis supridores de dinheiro mapeando oportunidades de obtenção de fundos. A missão do projeto foi definida no sentido de prover apoio social para a comunidade fornecendo informações aos pais sobre aspectos da criação de seus filhos, envolvendo saúde, educação, etc.

Quando o projeto foi iniciado, não se vislumbrava onde ele poderia parar, seu futuro no longo prazo, mas duas coisas eram muito claras: quem seriam os clientes e que tipo de produto estariam oferecendo. Os clientes seriam os pais de crianças e adolescentes que, de alguma maneira, tivessem acesso à Internet, 
independentemente de como isso pudesse ocorrer, ou seja, tanto para os que tivessem um computador em casa como aqueles que acessassem de algum lugar como escola, posto de assistência médica, vizinhos, clubes de bairros etc. O produto contendo a informação específica deveria ser disponibilizado dentro de um formato denominado de conteúdo temático. Tais conteúdos seriam produzidos de acordo com algumas especificações e formatos, disponíveis para os consumidores da Internet. As questões referentes a que e como fazer eram os principais aspectos na identificação dos conteúdos e as três empreendedoras se dedicavam à identificação das questões mais importantes e prioritárias.

Como a Internet foi definida como o veículo para alcançar os clientes, seria importante identificar os fornecedores da informação, que poderiam prover e manter respeito, credibilidade e valor para o site, por parte dos clientes. Especialmente devido ao conhecimento pessoal das três empreendedoras, vários médicos e psicólogos se ofereceram, gratuitamente, para gerar os conteúdos temáticos necessários para materialização do produto a ser oferecido à sociedade. Fazer recomendações aos pais, que poderiam imediatamente utilizá-las, implicaria em risco significativo e um engano ou mal entendido poderia destruir rapidamente uma imagem ainda em construção. Conseqüentemente, os supridores de conteúdos temáticos seriam críticos para o sucesso do projeto, iniciado no ano 2000; como conseqüência, ter acesso ao grupo produtor dos referidos conteúdos constitui-se em diferencial competitivo muito significativo. Com o passar do tempo, os clientes, pais em geral, passaram a se constituir em importante fonte de direcionamento sobre quais novos conteúdos deveriam ser priorizados e produzidos. Nesse tipo de projeto Internet, é comum a existência de trabalhos em que as parcerias sem desembolso, verdadeiros escambos, proporcionem serviços e benefícios mútuos, a partir de troca de oportunidades, tais como menção do nome, divulgação de imagem e coisas do gênero.

Um lugar para ser considerado como ponto de referência passou a ser necessário para os agentes do projeto, sendo que uma sala foi disponibilizada por um amigo das três empreendedoras, devido à confiabilidade e percepção do impacto social que o projeto estaria proporcionando. Lá foi acomodada a pequena estrutura organizacional que transformou a idéia em conteúdo e proporcionava aos clientes o acesso a informações. Apesar de que o investimento necessário não se constituía em valor muito relevante, ele era essencial para compra e manutenção de equipamentos, contratação de profissionais para gerenciar o site e outras despesas administrativas normais a qualquer projeto que se pretenda estruturar. No início do projeto, a grande prioridade era a sua sobrevivência, mesmo em detrimento de controle ou melhor alternativa de operacionalização.

Uma organização tem dificuldades de obter patrocínio no início de suas atividades pois precisa mostrar aspectos positivos e de eficiência. Num dado momento, dezembro de 2000 , tendo cerca de 4.000 visitantes/mês, as três empreendedoras sentiram que seria o momento adequado para encontrar um patrocinador que oferecesse apoio financeiro para o projeto. Uma empresa farmacêutica era a opção ideal dadas as possibilidades de uso de imagem para ambos os lados, além da quase imediata empatia mútua dos negociadores, o que gerou condições de um acordo de patrocínio muito útil nessa fase dos acontecimentos. O apoio financeiro funcionou muito bem por um período de dois anos, espaço de tempo considerado pelos patrocinadores como adequado a esse tipo de projeto. Depois disso, o apoio financeiro cessou e os gastos continuaram...

\section{CONVERSAS DE SÓCIAS $\mathbb{E}$ DECISÕES ESTRATERGICAS}

Cida estava preocupada em identificar alternativas para prolongar o ciclo de vida e manter a entidade sadia, com vigor. No momento, uma importante vantagem competitiva para o projeto Clicfilhos é o fato de ser o único no país, com as a quali- 
dade e alcance que ele tem. Levando em conta a história do website, o final do suporte de patrocínio trouxe importantes reflexões, que deveriam orientar decisões. Tais reflexões foram discutidas numa reunião sendo o diálogo reproduzido:

Cida:"Acho que chegou a hora de decidir pelo crescimento consistente do projeto ou seu abandono. O crescimento exige mais recursos e nenhuma de nós quer dispor de recursos próprios adicionais para atender às demandas geradas pela necessidade de investimentos."

Celiza: "É verdade. Bom, não importa qual alternativa a escolher, um agente externo será necessário, pois, na alternativa de continuidade do site, o crescimento exigirá mais recursos para investir em tecnologia e pessoas. No caso de venda, qual será o parceiro adequado no sentido de manter alguns dos seus serviços à comunidade, um preço justo pelos ativos da empresa evitando a percepção de sermos umas perdedoras por extinguir o projeto?"

Milena:"Nós sabemos que as aplicações referentes ao ensino e aprendizagem utilizando os recursos da Internet ainda estão em um estágio inicial e o potencial é considerado significativamente alto para quem estiver preparado. Além disso, a nova equipe governamental deve enfatizar o uso da Internet na educação e nos projetos sociais, especialmente devido à flexibilidade e baixo custo relativo. Quem estiver operando deve obter algum tipo de apoio financeiro."

Celiza:"Isso é verdade, mas acho que não podemos esperar. Precisamos ter um rumo."

Milena:"Mas nós temos. O que está faltando é o financiamento. Nesse tipo de atividade não dá para contar com outro tipo de recurso que não sejam as doações e o nosso dinheiro."

Cida:"Estava pensando nas nossas alternativas e fiz uma tabela com uma listinha de opções para discutir com vocês e verificar outras que não identifiquei."

Tabela 1. Alternativas para o futuro do website

\begin{tabular}{|c|c|c|c|c|c|}
\hline Descrição & $\begin{array}{l}\text { Nada } \\
\text { fazer }\end{array}$ & $\begin{array}{l}\text { Cessar as } \\
\text { atividades }\end{array}$ & $\begin{array}{c}\text { Incrementar as } \\
\text { atividades }\end{array}$ & $\begin{array}{c}\text { Vender da } \\
\text { forma como } \\
\text { se encontra } \\
\text { (gestoras } \\
\text { não } \\
\text { continuam) }\end{array}$ & $\begin{array}{c}\text { Venda } \\
\text { (gestoras } \\
\text { continuam) } \\
\text { Ou fusão } \\
\text { com outra } \\
\text { entidade }\end{array}$ \\
\hline $\begin{array}{l}\text { Investimento } \\
\text { necessário }\end{array}$ & $\begin{array}{l}\text { Capital de } \\
\text { giro }\end{array}$ & Nenhum & $\begin{array}{c}\text { Capital } \\
\text { de giro e } \\
\text { equipamentos } \\
\text { Produtos }\end{array}$ & Nenhum & Nenhum \\
\hline Fornecedores & Nenhum & Nenhum & $\begin{array}{c}\text { Equipamentos } \\
\text { Suporte na Internet }\end{array}$ & Nenhum & Nenhum \\
\hline Clientes & Pais & Nenhum & $\begin{array}{c}\text { Pais } \\
\text { Usuários de } \\
\text { web e-mails } \\
\text { Estudantes }\end{array}$ & $\begin{array}{l}\text { Pais } \\
\text { (nenhum } \\
\text { controle) }\end{array}$ & $\begin{array}{l}\text { Pais } \\
\text { (nenhum } \\
\text { controle) }\end{array}$ \\
\hline Produto & $\begin{array}{l}\text { Conteúdos } \\
\text { temáticos } \\
\text { e venda } \\
\text { de lista } \\
\text { de e-mails }\end{array}$ & Nenhum & $\begin{array}{c}\text { Conteúdos tematicos } \\
\text { Venda de lista de } \\
\text { e-mails } \\
\text { Cursos de ensino à } \\
\text { distância Suporte de } \\
\text { imagem }\end{array}$ & $\begin{array}{l}\text { Conteúdos } \\
\text { temáticos }\end{array}$ & $\begin{array}{l}\text { Conteúdos } \\
\text { temáticos }\end{array}$ \\
\hline
\end{tabular}


Cida: “A primeira delas é nada fazer. Por ora, claro. Essa alternativa é muito tentadora devido ao fato de que os recursos adicionais são relativamente pequenos. Esperar o tempo passar poderia ser uma alternativa que permitiria a identificação de outras alternativas mais à frente. Nessa situação, seria necessário reduzir as despesas correntes para um nível mínimo com empregados em tempo parcial. Poderíamos vender lista de e-mails para gerar alguma receita."

Milena:"Não gosto dessa idéia. É como hibernar. Como vamos nos sentir? E os funcionários? Vender mailing list não é fácil."

Celiza: “É. Eu também não gosto muito dessa idéia, mas vamos ver se temos outras melhores."

Cida:"Tá bom. Pensei no final do projeto. Simplesmente fechar o website, vender os equipamentos e os conteúdos e dispensar os funcionários e clientes. Nesse caso, os ativos intangíveis seriam destruídos, pondo fim ao benefício proporcionado à comunidade."

Milena e Celiza em coro: "Nem pensar!"

Cida: "Como assim? Vocês acham que essa é a pior alternativa? Eu não estou segura sobre isso. Vamos em frente. A outra alternativa seria incrementar as atividades do website. Esta seria a mais agressiva das alternativas tentando fazer o site mais sofisticado e eficiente, a partir de novos investimentos. Neste caso, um novo patrocinador seria identificado para viabilizar os investimentos requeridos."

Celiza: “Cida você só trocou o problema pois o que nos falta é dinheiro e nessa alternativa nós temos que encontrar outro sócio/patrocinador."

Cida: "É verdade. Nós não estamos encontrando financiamento para os serviços atuais, mas será que não poderemos encontrar para novos serviços?"

Milena: "É complicado! O que temos a oferecer é a confiabilidade em um tipo de serviço. Ao ampliar, mudamos a nossa cara."

Cida: "Pensei também na venda do website da forma como se encontra. Apesar de factível, no momento, esta alternativa não foi seriamente considerada porque exigia uma proposta firme, que não era disponível naquele momento."

Celiza: "Por que alguém compraria? Na verdade o que seria comprado?"

Cida: "Isso eu não sei. Só estou pensando. Bom, tenho mais uma alternativa: fusão com outra entidade. Essa alternativa pode ser implementada, pois existe uma oferta firme de um dono de escola. Você está lembrada?"

Celiza: "Por que não pensamos no que temos a oferecer e, para quem?"

Cida: "Eu fiz alguma coisa nesse sentido. Listei alguns potenciais interessados: uma escola, uma organização não governamental, uma empresa multinacional desejosa de dispor de uma estrutura para pronta utilização dando apoio à sua imagem institucional, em decorrência de alguma demanda da sua estratégia de negócios. Veja a minha tabela 2." 
Tabela 2. Ativos disponíveis da perspectiva das alternativas

\begin{tabular}{|c|c|c|c|}
\hline Descrição & Escola & ONG & $\begin{array}{c}\text { Empresa } \\
\text { multinacional }\end{array}$ \\
\hline $\begin{array}{l}\text { Tangíveis } \\
\text { Intangíveis }\end{array}$ & $\begin{array}{l}\text { Equipamentos } \\
\text { Conteúdos atuais } \\
\text { Capacidade de } \\
\text { produzir futuros } \\
\text { conteúdos } \\
\text { Experiência com } \\
\text { comunicação por } \\
\text { meio de website } \\
\text { Listas de e-mail } \\
\text { Sinergia em cursos } \\
\text { de ensino à } \\
\text { distância } \\
\text { Imagem positiva a } \\
\text { propaganda }\end{array}$ & $\begin{array}{l}\text { Equipamentos } \\
\text { Conteúdos atuais } \\
\text { Capacidade de } \\
\text { produzir futuros } \\
\text { conteúdos } \\
\text { Experiência com } \\
\text { comunicação por } \\
\text { meio de website } \\
\text { Listas de e-mail } \\
\text { I magem positiva a } \\
\text { propaganda }\end{array}$ & $\begin{array}{l}\text { Equipamentos } \\
\text { Conteúdos atuais } \\
\text { Capacidade de } \\
\text { produzir futuros } \\
\text { conteúdos } \\
\text { Experiência com } \\
\text { comunicação por } \\
\text { meio de website } \\
\text { Listas de e-mail } \\
\text { I magem positiva a } \\
\text { propaganda }\end{array}$ \\
\hline
\end{tabular}

Milena: "Imagino que, para a Organização Não Governamental (ONG), os conteúdos atuais simplesmente correspondam a uma maneira de proporcionar benefícios à sociedade. Ela pode atribuir valor confrontando o custo de atingir tal propósito desenvolvendo ela própria os conteúdos. Dessa maneira, o projeto é a essência das suas atividades."

Cida: "É mais ou menos isso."

Milena: "Para a empresa multinacional, por exemplo, o website poderia ser parte do seu esforço de imagem para melhorar a empatia dos clientes com a marca. Pode ser uma opção a fim de economizar os gastos caso ela quisesse construir um similar."

Cida: "Ok. O meu raciocínio é esse."

Celiza: "Para a escola, o website é um serviço adicional que ela poderia oferecer para os alunos atuais e futuros, como forma de proteção que teria contra a concorrência."

Milena: "O que você considerou como benefícios procurados pelos potenciais interessados?"

Cida: “Ah! Eu separei em vários benefícios. O primeiro é a capacidade de produzir novos conteúdos. I sso é especialmente importante e está ligada às nossas habilidades, graus de sensibilidade, experiência e networking pessoais."

Celiza: "Isso é importante, mas você está falando de nós. Sem nossa presença, ele não existe."

Milena: "Nós ou alguém com as nossas características."

Cida: "O outro benefício possível é que a experiência com a comunicação por meio do website pode ser muito importante para todos os tipos de compradores potenciais e depende da prioridade que a presença do website representa para a estratégia da organização. Por outro lado, caso essa experiência já faça parte do capital intelectual da entidade, ela não seria, exceto a curto prazo, importante nessa operação." 
Milena: “Quanto vale isso?"

Cida: "Bom, isso é outro problema. Vamos em frente. Sempre poderemos vender a lista de e-mails. É um ativo indireto que, em alguns casos, poderia ser comercializado. Pode ser valioso para algum tipo de organização dispor de mailing list de pais, por faixa etária de filhos etc."

Celiza: "Cida. A receita é pequena nesse tipo de operação. Aliás, é por isso que estamos buscando outras alternativas."

Cida: "Vamos em frente. Pensei também no apoio ao treinamento/ensino à distância. Pode ser uma interessante possibilidade devido à sinergia da imagem e credibilidade do nome. Nesse caso, o projeto requer recursos adicionais específicos."

Milena: "Esse é o tipo de idéia que exige alguém muito específico."

Cida: "O último item da minha lista é a imagem para propósitos de propaganda. É difícil de separar dos demais itens. A credibilidade é importante para vários agentes e só é mantida se a qualidade dos serviços for mantida."

Celiza: "Acho que por hoje está bem. Vamos pensar nas alternativas e voltaremos a conversar."

Milena: "Está bem. Vocês se lembram das propostas que tivemos no passado? E se nós resgatássemos e tentássemos ajustar a proposta aos nossos anseios?"

\section{ANALISANDO UMIA PROPOSTA}

Embora o brainstorming fosse necessário, era fundamental para as três ter percepção do que o ambiente externo estaria aceitando. Nesse sentido, existiam duas propostas de compra do projeto que haviam sido feitas algum tempo atrás, antes mesmo do final do patrocínio e agora por elas resgatadas. Uma delas feita pelo dono de uma escola que considerava que o site poderia se tornar parte do negócio da escola, como um recurso que fortalecesse a sua posição no mercado, adicionando serviços ao seu negócio. Dessa forma, funcionaria como um benefício adicional, exclusivo para a escola, mudando a perspectiva de participação social que permeava o início do projeto. Como proposta de pagamento, o novo agente propunha a troca de quotas de participação, ou seja, uma operação sem caixa para as três sócias. No lugar de pagamento em dinheiro, elas se transformariam em sócias minoritárias da escola. Tratava-se de diferentes tamanhos de negócios, com evidente complexidade de evidenciação para ambos os lados, já que uma informação fundamental, o valor de cada negócio precisaria ser apurado para determinar o preço da quota a ser constituída. Uma coisa parecia certa: o papel das três empreendedoras seria profundamente alterado nesse contexto, trocando a figura de donas de um site pela posição, na melhor das hipóteses, empregadas de uma atividade economicamente maior. As três sócias consideraram a idéia da troca de quotas de participação muito desfavorável e o investidor fez uma proposta alternativa, que consistia do seguinte:

- $\quad$ Formalmente falando, as atuais proprietárias não mais seriam donas, mas sim empregadas do ofertante;

- $\quad$ Elas assumiam o compromisso de ficar na entidade durante 36 meses como horizonte de envolvimento e os pagamentos seriam mensais; 
- Compromisso de produzir 10 conteúdos temáticos por semestre, no intervalo de 36 meses;

- Caso, ao final de dois semestres as receitas não crescessem, os pagamentos mensais cessariam e o acordo seria cessaria;

- Os pagamentos mensais para as três sócias considerando a taxa de $20 \%$ sobre o acréscimo da receita, recalculada por trimestre, sendo garantido um valor mínimo de $\$ 6.000 /$ mês. Computando os números, o pagamento inicial definido foi de $\$ 6.000$, que se mostraram próximos aos números por elas desejados; e

- Algumas penalidades foram definidas: se um dos dois lados desistisse no meio do caminho, existiria uma penalização, uma multa de $\$ 30.000$ para ser paga à outra parte.

Ao final da reunião as três empreendedoras pediram um tempo para pensar e foram conversar com os respectivos travesseiros. Não parecia fácil decidir quando as alternativas não são aquelas que gostaríamos de implementar.

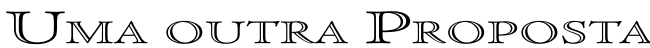

A outra proposta foi feita por um concorrente da escola descrita. Era o dono de uma outra escola que também havia se interessado pela possibilidade de ter o site como instrumento de apoio aos seus alunos. Na época, elas informaram a esse novo interessado que não estavam em processo de negociação mas que já que existia uma proposta firme na mesa e, embora ainda não decidida, existia um compromisso ético de precedência em relação ao primeiro proponente.

O segundo interessado ofereceu para a aquisição pura e simples dosite com pagamento à vista $\$ 35.000$. Elas perguntaram sobre a razão do interesse pelo site e quem continuaria gerenciando e produzindo os conteúdos. Perceberam que o segundo interessado não estava preocupado em mantê-las, mas sim em se apropriar dos direitos sobre o site, o que se revelava uma postura diametralmente distinta do outro agente, que, claramente, desejava dispor dos meios para manter osite com qualidade adequada de atendimento dos clientes.

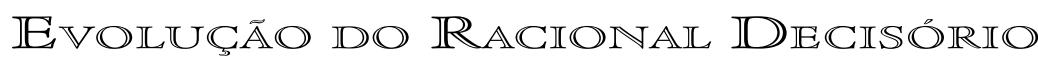

Depois de alguma discussão, ficou acertado que, em primeiro lugar, seria necessário avaliar questões que parecessem objetivas e, nesse sentido, o fluxo de caixa das opções parecia ser uma forma de começar, de maneira produtiva, a discussão. Entradas e saídas de caixa foram projetadas para um período de 36 meses, já que era o horizonte acordado como de potencial benefício para a transação. Alguns dados foram apresentados nas Tabelas 3 e 4. Inicialmente, a afinidade com os números não parecia ser muito grande, o grau de incerteza que proporcionavam era grande e era entendida pelas empreendedoras como um grande empecilho. Paulatinamente, foram percebendo que alguns dados poderiam ser ajustados e apresentados com a perspectiva de risco que implicavam, o que foi proporcionando uma crescente confiança no processo de projeção. A partir dela, projeções foram desenvolvidas com o objetivo de obter o Valor Presente do Fluxo de Caixa de cada opção para proporcionar o impacto econômico das alternativas. A taxa de desconto a ser utilizada pelas empreendedoras foi de $15 \%$ aa, por ser adequada a investimentos de risco semelhante. 
Tabela 3. Dados básicos das entradas de caixa pertinentes às opções - em \$

\begin{tabular}{|c|c|c|c|c|c|c|}
\hline Descrição & $\begin{array}{l}\text { Nada } \\
\text { fazer }\end{array}$ & $\begin{array}{l}\text { Cessar as } \\
\text { atividades }\end{array}$ & $\begin{array}{c}\text { I ncremento } \\
\text { de } \\
\text { atividades }\end{array}$ & $\begin{array}{c}\text { Venda } \\
\text { (gestoras } \\
\text { não } \\
\text { continuam) }\end{array}$ & $\begin{array}{c}\text { Venda } \\
\text { ( gestoras } \\
\text { continuam) } \\
36 \text { meses }\end{array}$ & $\begin{array}{c}\text { Venda } \\
\text { (gestoras } \\
\text { continuam) } \\
12 \text { meses }\end{array}$ \\
\hline $\begin{array}{c}\text { Elementos } \\
\text { do fluxo } \\
\text { de entrada }\end{array}$ & $\begin{array}{l}\text { Venda de } \\
\text { lista de } \\
\text { e-mails, } \\
\text { sendo \$ } \\
500 / \text { mês }\end{array}$ & $\begin{array}{l}\text { Venda de } \\
\text { ativos tangi- } \\
\text { veis (equipa- } \\
\text { mentos), } \\
\text { sendo \$1.500 } \\
\text { numa única } \\
\text { vez. } \\
\text { Venda dos } \\
\text { conteúdos } \\
\text { disponíveis, } \\
\text { sendo stima- } \\
\text { do o valor de } \\
\text { mercado de } \\
\$ 5.000, \text { uma } \\
\text { única vez }\end{array}$ & $\begin{array}{l}\text { Venda de } \\
\text { lista de e- } \\
\text { mails, por \$ } \\
500 / \text { mês } \\
\\
\text { Conteúdos } \\
\text { (prestação de } \\
\text { serviços), } \\
\text { sendo \$ } \\
3.000 / \text { mês, } \\
\text { após } 3 \text { meses } \\
\text { do início da } \\
\text { projeção } \\
\text { Outros } \\
\text { serviços } \\
2.500 / \text { mês, } \\
\text { após } 3 \text { meses } \\
\text { do início da } \\
\text { projeção }\end{array}$ & $\begin{array}{l}\text { Venda da } \\
\text { entidade com } \\
\text { todos os seus } \\
\text { ativos, sendo } \\
\$ 35.000 \text { uma } \\
\text { única vez }\end{array}$ & $\begin{array}{l}\text { Pagamento } \\
\text { pela } \\
\text { participação } \\
\text { das atuais } \\
\text { gestoras, } \\
\text { sendo \$ } \\
6.000 / \text { mês }\end{array}$ & $\begin{array}{l}\text { Pagamento } \\
\text { pela } \\
\text { participação } \\
\text { das atuais } \\
\text { gestoras, } \\
\text { sendo \$ } \\
6.000 / \text { mês }\end{array}$ \\
\hline $\begin{array}{l}\text { Observa- } \\
\text { ções }\end{array}$ & & \begin{tabular}{|l|} 
Existiria \\
mercado para \\
os conteúdos \\
para outra \\
finalidade que \\
não o site? \\
Quais as \\
reações dos \\
colaboradores \\
que nada \\
cobraram?
\end{tabular} & & $\begin{array}{l}\text { Seria cobrado } \\
\text { algum } \\
\text { compromisso } \\
\text { do adquirente } \\
\text { em termos de } \\
\text { serviços } \\
\text { futuros e } \\
\text { finalidade } \\
\text { social? }\end{array}$ & & \\
\hline
\end{tabular}

Por sua vez, as saídas de caixa identificadas foram as seguintes:

Tabela 4. Dados básicos das saídas de caixa pertinentes às opções - em \$

\begin{tabular}{|c|c|c|c|c|c|c|}
\hline Descrição & Nada fazer & $\begin{array}{l}\text { Cessar as } \\
\text { atividades }\end{array}$ & $\begin{array}{c}\text { I ncremento } \\
\text { de } \\
\text { atividades }\end{array}$ & \begin{tabular}{|c|} 
Vender da \\
forma como \\
se encontra \\
(gestoras não \\
continuam)
\end{tabular} & $\begin{array}{c}\text { Venda } \\
\text { (gestoras } \\
\text { continuam) } \\
36 \text { meses }\end{array}$ & $\begin{array}{c}\text { Venda } \\
\text { (gestoras } \\
\text { continuam) } \\
12 \text { meses }\end{array}$ \\
\hline $\begin{array}{l}\text { Elementos } \\
\text { do fluxo } \\
\text { de saída } \\
\\
\text { Observa- } \\
\text { ções }\end{array}$ & $\begin{array}{l}\text { Reduzir os } \\
\text { gastos com } \\
\text { pessoal } \\
\text { para } \\
\$ 500 / \text { mês } \\
\\
\text { Gastos de } \\
\text { escritório } \\
\text { de } \\
\$ 200 / \text { mês }\end{array}$ & $\begin{array}{l}\text { Gastos com } \\
\text { dispensa de } \\
\text { funcionários } \\
\text { de } \$ 3.000 \\
\text { uma única } \\
\text { vez }\end{array}$ & $\begin{array}{l}\text { Investimento } \\
\text { de } \$ 15.000 \\
\text { no momento } \\
\text { inicial } \\
\text { Gastos com } \\
\text { pessoal de \$ } \\
1.000 / \text { mês } \\
\text { Gastos de } \\
\text { escritório de } \\
\$ 300 / \text { mês }\end{array}$ & \begin{tabular}{|l|} 
Gastos com \\
dispensa de \\
funcionários, \\
de $\$ 3.000$ \\
uma única vez \\
\\
\\
Os funcionarios \\
poderiam \\
continuar na \\
nova empresa?
\end{tabular} & $\begin{array}{l}\text { Gastos com } \\
\text { dispensa de } \\
\text { funcionários } \\
\text { de } \$ 3.000 \\
\text { uma única } \\
\text { vez }\end{array}$ & $\begin{array}{l}\text { Gastos com } \\
\text { dispensa de } \\
\text { funcionários } \\
\text { de } \$ 3.000 \\
\text { uma única } \\
\text { vez }\end{array}$ \\
\hline
\end{tabular}


As pessoas podem argumentar que reclamar apenas não faz com que problemas sejam resolvidos devido ao fato de que o dilema está lá, presente e ainda não resolvido. Incerteza sobre projeções dos números corresponde a parte da vida das pessoas e organizações, não se constituindo em privilégio das organizações de porte menor, ou menos estruturadas. Os diferentes agentes envolvidos não deveriam ver os fatos como problemas mas sim como interessantes oportunidades.

Sonhar é uma importante parte de qualquer tipo de projeto no que se refere ao envolvimento das pessoas. Neste caso, três pessoas iniciaram um projeto com uma missão e conotação especiais que deveriam ser mantidas ao longo de toda a vida do projeto, no sentido de que a sua essência pudesse ser preservada. Qual seria o valor disso? Nessa situação, não se pretende discutir se uma decisão é boa ou ruim, mas sim o grau de conforto proporcionado pelo processo decisório evidenciado. A pergunta ainda está no ar: o que fazer?

\section{BIBIIOGRAFIA RECOMIENDADA PARA AS QUESTÕES FINANGEIRAS}

Damodaran, A. Investment valuation, New York: Wiley, 1996

Hendriksen, E. \& Breda, M. Accounting theory, 5th. Edition. Boston: Irwin, 1992

Rappaport, A. Creating Shareholder Value, New York, Free Press, 1997

Stewart, G.Bennett, III. The Quest for Value, New York, Harper Business, 1991

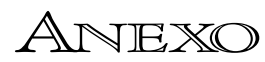

INSTRUÇÕES PARA OS PROFESSORES

OBIETIVO DE $\mathbb{E} \mathbb{N}$ SINO

Analisar um caso que mistura vários ingredientes, embora o foco seja voltado para o empreendedorismo em uma organização de pequeno porte ligada à Internet, tratando as conseqüências dos possíveis direcionamentos adotados pelas empreendedoras.

O caso exige decisão sobre direcionamento futuro do projeto e as alternativas que proporcionam diferentes perspectivas e implicações em termos de fluxo de caixa futuro, poder e motivação sobre as pessoas envolvidas.

I nformações do tipo por quanto e como correspondem a uma parte da questão a ser considerada, mas o caso demanda mais do que isso; quais informações e o que fazer com elas correspondem aos aspectos mais críticos do caso, fazendo com que poucas informações numéricas sejam oferecidas, ainda que os conceitos necessários para tratá-las sejam necessários ao longo da narrativa.

Avaliação de uma entidade é um tipo de técnica que foi desenvolvida para suportar decisões em organizações de grande porte considerando, inicialmente, ativos tangíveis. A análise reporta o caso de uma organização de pequeno porte, baseada quase que exclusivamente em ativos intangíveis.

des educacionais:

Este caso é recomendado, principalmente, para as seguintes oportunida-

1. Alunos de graduação de administração de empresas e contabilidade: disciplinas que tratem o empreendedorismo. Em geral trata-se de alunos em final de curso, que tenham tido exposição a conceitos de administração, contabilidade, finanças, estratégia e empreendedorismo. 
2. Alunos de MBA, em disciplinas que tratem o empreendedorismo, desde que tenham disciplinas de administração, contabilidade, finanças, estratégia e empreendedorismo como pré-requisitos

\section{TEMAS $\mathbb{E}$ CONCEITOS NECESSÁRIOS Ã DISCUSSÃO} seguintes:

Os principais temas implicitamente incorporados à discussão do caso são os - Evolução de negócios

O maior foco desse ponto diz respeito à evolução da entidade propriamente dita, o que pode ser previsível em alguns casos, mas deve estar na ordem do dia, sendo repensada e redirecionada, periodicamente, em decorrência das estratégias possíveis.

\section{- I Internet no processo de criação de valor}

Os negócios com ou na Internet são singulares no que se refere à existência exclusivamente de ativos intangíveis que proporcionam a esse tipo de operação uma visão particular de risco. A análise dos processos requeridos para a atividade deve proporcionar uma adequada fonte de subsídios para identificar o potencial de geração de valor.

\section{- Sentimentos, emoções e motivação no relacionamento de negócios}

As pessoas agem e reagem de acordo com crenças, sonhos e expectativas. É difícil e inútil excluir tais aspectos do processo decisório, ainda que a sua presença aumente a complexidade e mesmo a incerteza.

\section{- I mpacto social e responsabilidade versus oportunidades de retorno}

Alguns projetos são especiais do ponto de vista do comprometimento que as pessoas que desejam vê-los em ação. As percepções da sociedade sobre os compromissos das pessoas com tais projetos são importantes para o seu desenvolvimento, independentemente do cinismo ou real envolvimento que se encontre nos diversos projetos.

\section{- Financiamento do Projeto}

Nenhum investimento é possível sem considerar a perspectiva de financiamento. Alguns projetos percebidos como perfeitos e contributivos simplesmente morreram por ausência de fundos, o que, nos projetos com conotação social, é ainda mais grave.

\section{Conceitos e I nformações Necessárias:}

- Negócios em geral: produtos/serviços, mercados e visão estratégica da entidade

- $\quad$ Finanças: fluxo de caixa descontado, estrutura de capital, custo de oportunidade, projeto de investimento, capital de giro, alternativas de financiamento e diferentes perspectivas de risco

- Impacto dos serviços do site na comunidade: conceitos, indicadores e mensuração

\section{QUESTOUES PARA OS PARTICIPANTES

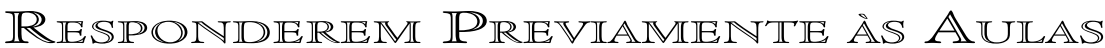

As seguintes questões devem ser endereçadas aos participantes, respondidas antes da discussão do caso de forma individual:

1. Que tipos de informações são necessárias para atender a demanda do caso?

2. O que realmente seria importante numa discussão do dilema apresentado?

3. Sem se limitar às alternativas oferecidas no texto do caso, estimulando a criatividade, quais alternativas de curso de ação seriam identificadas e poderiam ser consideradas na solução do caso? 
4. Analisar as vantagens e desvantagens de cada uma das alternativas identificadas, levando em conta as empreendedoras, os funcionários, os clientes e fornecedores

5. Já que a taxa de custo de oportunidade foi oferecida na redação do caso, para ser coerente com a teoria de finanças, o que ela deveria levar em conta?

6. Calcular o impacto financeiro de cada alternativa apurando o Valor Presente Líquido das várias opções identificadas DO PONTO DE VISTA DAS EMPREENDEDORAS. Caso identifique algum item da projeção não disponível, estime e explicite como premissa.

7. Como lidar com o equilíbrio entre a satisfação material e as necessidades do perfil empreendedorista?

8. Nesta situação, no lugar das empreendedoras, o que você faria? Justifique.

\section{COMIO CONDUZIR A SESSÃO}

A condução da sessão tem por pressuposto que os participantes tenham tido acesso ao caso, estudado o seu desenvolvimento, esclarecido as questões conceituais apresentadas e respondido às questões propostas. O plano de desenvolvimento do caso, em sala de aula, é apresentado abaixo:

\section{AqueCIMIENTO: $\mathbb{M}$ IOSTRAR O IMIPACTO

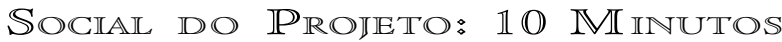

Recomendação: O primeiro passo para o desenvolvimento do caso referese à empatia que pode ser desenvolvida falando sobre os problemas referentes às crianças e adolescentes e à necessidade de contínuo aprendizado que os pais têm para enfrentar o desafio que é criar filhos (...). Ter informações confiáveis, consistentes e claras é algo importante para a sociedade. A seqüência da condução do evento deve levar em conta:

- Identificar quem tem filhos pequenos ou adolescentes na platéia

- Perguntar algo específico sobre criar filhos para alguns participantes, que ele gostaria de saber. A condução do tema a ser abordado deve ser planejada pelo docente que aplica o caso

- $\quad$ Acessar o site e tentar buscar respostas para as perguntas levantadas

- Discutir grau de satisfação dos participantes em termos de informações

- Mostrar o www. clicfilhos.com.br

\section{Valor, Resultados $\mathbb{E}$ ATrVOS: $2 \mathbb{O} \mathbb{M}$ INUTOS}

Recomendação: O principal foco desse passo é a abertura da discussão sobre os ativos presentes num site, tanto no momento presente como impacto futuro. Os principais aspectos a discutir:

- Identificar os atuais serviços proporcionados pelo site. Identificar aqueles que possam ser desenvolvidos no futuro;

- Debater: quais produtos e serviços, dentro da missão implícita da entidade, podem agregar valor? Indicar prioridades ou potencial de possibilidades;

- Identificar e discutir a existência de outros potenciais interessados pelo site (governamentais, comunitários, privados etc);

- Identificar e discutir as questões específicas da fusão de entidades, responsabilidades e riscos; e

- Explorar/ debater a questão do ciclo de vida dos produtos atuais e futuros, bem como os investimentos necessários, dentro da perspectiva de seqüência, previsibilidade e mesmo duração. 
Recomendação: Evidenciação da ligação entre valor e projeções financeiras é crítica e obter a credibilidade do modelo é o objetivo do analista e tomador de decisões. Os principais aspectos são:

- I Ientificar e discutir as premissas para o Fluxo de Caixa Descontado;

A definição do custo ponderado de capital das empreendedoras é necessária para descontar o fluxo de caixa das opções, referente ao período futuro. Particularmente, pelo fato de que a entidade Clicfilhos.com.br era financiada exclusivamente com recursos próprios, e as empreendedoras só teria projetos com o mesmo perfil de financiamento, a taxa de custo de oportunidade que seria usada seria aquela que elas poderiam obter em decorrência de investimentos em alternativas de risco assemelhado. Essa taxa, naquele momento seria de $15 \%$.

A abordagem fundamentalista requer o fluxo de caixa relevante dos elementos que possam ser identificados pelos agentes. Perspectivas de otimismo e pessimismo foram introduzidas na análise para obter a alternativa mais provável, oferecida às tomadoras de decisão.

- Identificar e discutir os prováveis cenários e suas simulações;

- Identificar e discutir os possíveis riscos e hierarquizar a aceitabilidade dos mesmos perante as decisões possíveis;

- Discutir com os participantes métodos possíveis para obtenção da projeção do valor; e

- Analisar e discutir as projeções do fluxo de caixa nos vários cenários

Tabela 5: Projeção das Entradas de Caixa em US\$

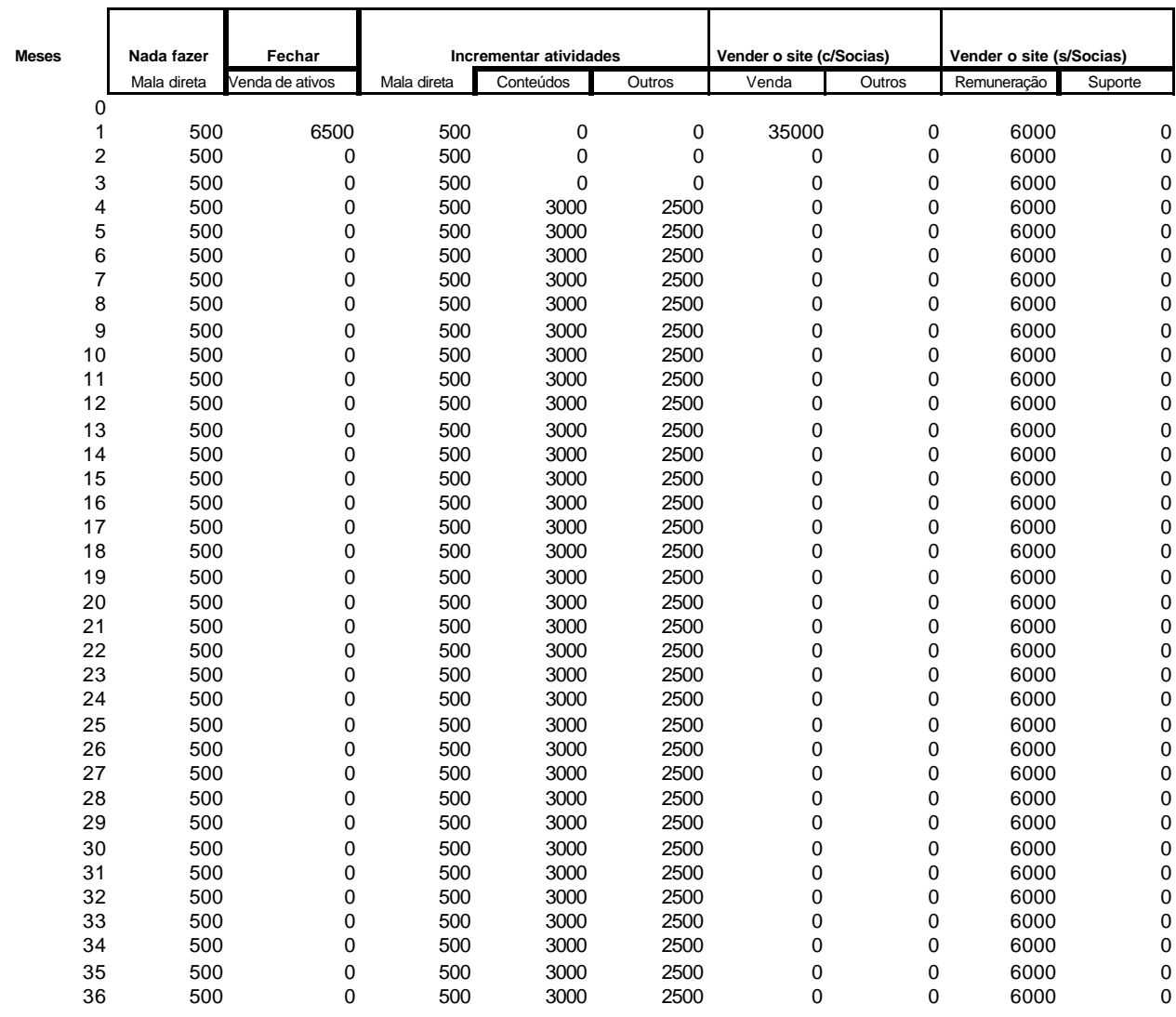


Tabela 6: Projeção das Saídas de Caixa em US\$

\begin{tabular}{|c|c|c|c|c|c|c|c|c|c|c|c|c|c|c|c|c|}
\hline \multirow[t]{2}{*}{ Meses } & \multicolumn{3}{|c|}{ Nada fazer } & \multicolumn{3}{|c|}{ Fechar } & \multicolumn{3}{|c|}{ Incrementar atividades } & \multicolumn{3}{|c|}{ Vender o site (sem sócias) } & & \multicolumn{3}{|c|}{ Vender o site (com as sócias) } \\
\hline & Funcionários & Materiais & Outros & Funcionários & Materiais & Outros & Funcionários & \begin{tabular}{l|l} 
Materiais \\
\end{tabular} & Outros & Funcionários & Materiais & Outros & & Funcionários & Materiais & Outros \\
\hline 1 & 1000 & 200 & 0 & 3000 & 0 & 0 & 1000 & 15000 & 0 & 3000 & 0 & & 0 & 3000 & 0 & 0 \\
\hline 2 & 500 & 200 & & 0 & 0 & 0 & 1000 & 300 & 0 & 0 & 0 & & 0 & 0 & 0 & 0 \\
\hline 3 & 500 & 200 & 0 & 0 & 0 & 0 & 1000 & 300 & 0 & 0 & 0 & & 0 & 0 & 0 & 0 \\
\hline 4 & 500 & 200 & 0 & 0 & 0 & 0 & 1000 & 300 & 0 & 0 & 0 & & 0 & 0 & 0 & 0 \\
\hline 5 & 500 & 200 & 0 & 0 & 0 & 0 & 1000 & 300 & 0 & 0 & 0 & & 0 & 0 & 0 & 0 \\
\hline 6 & 500 & 200 & 0 & 0 & 0 & 0 & 1000 & 300 & 0 & 0 & 0 & & 0 & 0 & 0 & 0 \\
\hline 7 & 500 & 200 & 0 & 0 & 0 & 0 & 1000 & 300 & 0 & 0 & 0 & & 0 & 0 & 0 & 0 \\
\hline 8 & 500 & 200 & 0 & 0 & 0 & 0 & 1000 & 300 & 0 & 0 & 0 & & 0 & 0 & 0 & 0 \\
\hline 9 & 500 & 200 & 0 & 0 & 0 & 0 & 1000 & 300 & 0 & 0 & 0 & & 0 & 0 & 0 & 0 \\
\hline 10 & 500 & 200 & 0 & 0 & 0 & 0 & 1000 & 300 & 0 & 0 & 0 & & 0 & 0 & 0 & 0 \\
\hline 11 & 500 & 200 & 0 & 0 & 0 & 0 & 1000 & 300 & 0 & 0 & 0 & & 0 & 0 & 0 & 0 \\
\hline 12 & 500 & 200 & 0 & 0 & 0 & 0 & 1000 & 300 & 0 & 0 & 0 & & 0 & 0 & 0 & 0 \\
\hline 13 & 500 & 200 & 0 & 0 & 0 & 0 & 500 & 300 & 0 & 0 & 0 & & 0 & 0 & 0 & 0 \\
\hline 14 & 500 & 200 & 0 & 0 & 0 & 0 & 500 & 300 & 0 & 0 & 0 & & 0 & 0 & 0 & 0 \\
\hline 15 & 500 & 200 & 0 & 0 & 0 & 0 & 500 & 300 & 0 & 0 & 0 & & 0 & 0 & 0 & 0 \\
\hline 16 & 500 & 200 & 0 & 0 & 0 & 0 & 500 & 300 & 0 & 0 & 0 & & 0 & 0 & 0 & 0 \\
\hline 17 & 500 & 200 & 0 & 0 & 0 & 0 & 500 & 300 & 0 & 0 & 0 & & 0 & 0 & 0 & 0 \\
\hline 18 & 500 & 200 & 0 & 0 & 0 & 0 & 500 & 300 & 0 & 0 & 0 & & 0 & 0 & 0 & 0 \\
\hline 19 & 500 & 200 & 0 & 0 & 0 & 0 & 500 & 300 & 0 & 0 & 0 & & 0 & 0 & 0 & 0 \\
\hline 20 & 500 & 200 & 0 & 0 & 0 & 0 & 500 & 300 & 0 & 0 & 0 & & 0 & 0 & 0 & 0 \\
\hline 21 & 500 & 200 & 0 & 0 & 0 & 0 & 500 & 300 & 0 & 0 & 0 & & 0 & 0 & 0 & 0 \\
\hline 22 & 500 & 200 & & 0 & 0 & 0 & 500 & 300 & 0 & 0 & 0 & & 0 & 0 & 0 & 0 \\
\hline 23 & 500 & 200 & 0 & 0 & 0 & 0 & 500 & 300 & 0 & 0 & 0 & & 0 & 0 & 0 & 0 \\
\hline 24 & 500 & 200 & & 0 & 0 & 0 & 500 & 300 & 0 & 0 & 0 & & 0 & 0 & 0 & 0 \\
\hline 25 & 500 & 200 & 0 & 0 & 0 & 0 & 500 & 300 & 0 & 0 & 0 & & 0 & 0 & 0 & 0 \\
\hline 26 & 500 & 200 & 0 & 0 & 0 & 0 & 500 & 300 & 0 & 0 & 0 & & 0 & 0 & 0 & 0 \\
\hline 27 & 500 & 200 & 0 & 0 & 0 & 0 & 500 & 300 & 0 & 0 & 0 & & 0 & 0 & 0 & 0 \\
\hline 28 & 500 & 200 & 0 & 0 & 0 & 0 & 500 & 300 & 0 & 0 & 0 & & 0 & 0 & 0 & 0 \\
\hline 29 & 500 & 200 & 0 & 0 & 0 & 0 & 500 & 300 & 0 & 0 & 0 & & 0 & 0 & 0 & 0 \\
\hline 30 & 500 & 200 & 0 & 0 & 0 & 0 & 500 & 300 & 0 & 0 & 0 & & 0 & 0 & 0 & 0 \\
\hline 31 & 500 & 200 & 0 & 0 & 0 & 0 & 500 & 300 & 0 & 0 & 0 & & 0 & 0 & 0 & 0 \\
\hline 32 & 500 & 200 & 0 & 0 & 0 & 0 & 500 & 300 & 0 & 0 & 0 & & 0 & 0 & 0 & 0 \\
\hline 33 & 500 & 200 & 0 & 0 & 0 & 0 & 500 & 300 & 0 & 0 & 0 & & 0 & 0 & 0 & 0 \\
\hline 34 & 500 & 200 & & 0 & 0 & 0 & 500 & 300 & 0 & 0 & 0 & & 0 & 0 & 0 & 0 \\
\hline 35 & 500 & 200 & 0 & 0 & 0 & 0 & 500 & 300 & 0 & 0 & 0 & & 0 & 0 & 0 & 0 \\
\hline 36 & 500 & 200 & 0 & 0 & 0 & 0 & 500 & 300 & 0 & 0 & 0 & & 0 & 0 & 0 & 0 \\
\hline
\end{tabular}

Tabela 7: Projeção do Valor Presente Líquido em US\$

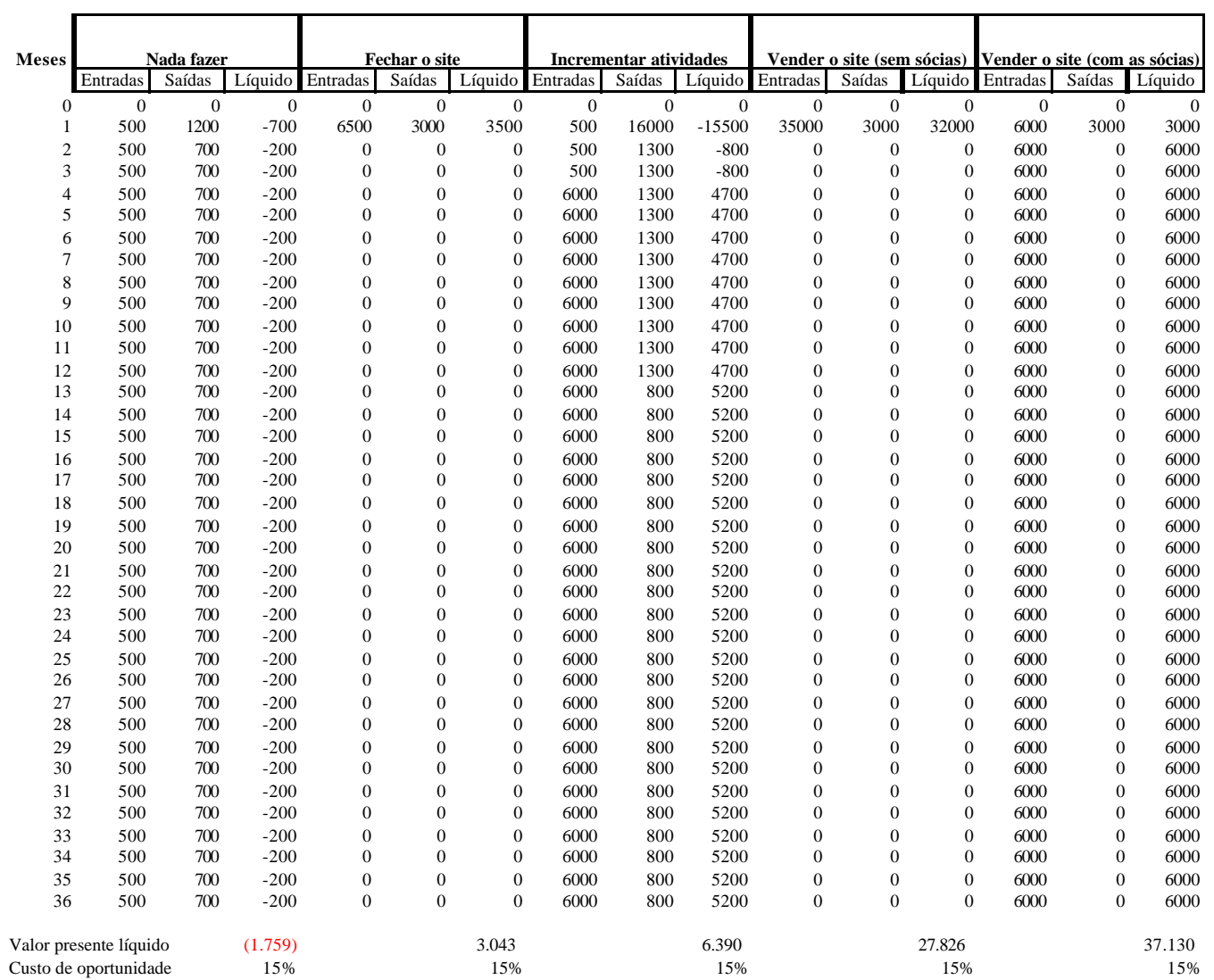


Recomendação: Números são importantes e devem apoiar o processo decisório. A ligação entre os assuntos objetivos e perspectivas é de fundamental importância para evitar/limitar frustrações no processo. Os principais aspectos a evidenciar são:

- I Ientificar e discutir os prós e contras: cauda de leão x cabeça de formiga

Em alguns momentos, escolhas desse tipo surgem: ocupar uma posição de destaque, de predominância em uma organização pequena, com grande liberdade e poder criativo, embora com restrições no que se refere às questões monetárias, normalmente mais difíceis nas empresas menores; por outro lado, atuar em uma organização maior, pode trazer diferentes aprendizados, maior status, embora, normalmente, com menor liberdade de atuação. O que se ganha e o que se perde nos dois extremos depende muito da situação envolvida e o processo decisório fica muito difícil, pois as prioridades para a escolha são muito voltadas para as características individuais dos tomadores de decisão. Na literatura não erudita o tipo de dilema apresentado é conhecido como decidir pela figura de ser, numa organização, cabeça de formiga ou ser cauda de leão...

- Identificar e discutir os possíveis futuros para as atuais proprietárias dosite

- Afinal... e o sonho? Diferentes perspectivas de benefícios

\section{DeCISÃo $\mathbb{E}$ ENCERTAMIENTO: $\mathbb{1} \mathbb{O}$ MLINUTUOS}

Recomendação: Principais aspectos a desenvolver são:

- Votação para identificar as alternativas e racional de cada eleitor;

- Discussão entre as possíveis alternativas; e

- Encerramento da sessão enfatizando os extremos da discussão: cauda de leão ou cabeça de formiga?

\section{$\mathbb{B} I B I I O G \mathbb{R} \mathbb{R} I \mathbb{R} \mathbb{R} C O \mathbb{M} \mathbb{E} \mathbb{N} \mathbb{A} D$}

Leenders, Michael R., Erskine, James A., Case research: the case writing process, Londres, Canada: Research and Publications Division, School of Business Administration, The University of Werstern, Ontário, 1973

Maximiano, Antonio C. A., SBRAGIA, Roberto, capítulo Método do Caso no Estudo da Administração. BOOG, Gustavo, coordenador, Manual de Treinamento e Desenvolvimento. São Paulo, Makron Books, 2001, páginas 81-96. 